\title{
453 - The effect of ageing in personality and emotions
}

Catarina Pedro ${ }^{1}$, Mariana Duarte ${ }^{2}$, Beatriz Jorge ${ }^{3}$, Daniela Freitas ${ }^{4}$

1 Hospital de Braga, Psychiatry Department, Braga, Portugal. e-mail: catarinap_fernandes@hotmail.com

2 Hospital de Beja, Psychiatry Department, Beja, Portugal. e-mail: mariana_mangas@hotmail.com

3 Hospital de Braga, Psychiatry Department, Braga, Portugal. e-mail: bea.negocios@gmail.com

4 Hospital de Braga, Psychiatry Department, Braga, Portugal. e-mail: danielafreitas84@gmail.com

Introduction: Personality and emotions have not been studied as thoroughly as cognition in old age. Recent research suggests personality changes across the entire life span, through middle age and even into old age. Thus, the previous assumption of stability in personality traits from early adulthood has been challenged and novel approaches to the study of personality development have emerged.

Objectives: The aim of this presentation is to describe the effects of the ageing process in personality and emotions.

Methods: A non-systematic review of the literature was performed on PubMed, PsycINFO and Web of science using selected keywords.

Results: When older adults compare their current and past selves, they usually perceive a subjective growth in personality. Descriptive research suggests that the big five personality characteristics (neuroticism, extraversion, openness, agreeableness and conscientiousness) remain generally stable over the lifespan, despite variations in life experiences. Some studies revealed age-related linear decrease in extraversion. One of the studies found that hearing impairment, already identified as a significant risk factor for social isolation, was related to this decline in extraversion. Although levels of neuroticism tends to go down over the course of adulthood, the increased vulnerabilities that accompany old age may amplify neurotic traits, increasing worries about physical health and memory, common features of depression in the elderly. Emotions, relative to more neutral knowledge and skills, increase in later years. Elderly have better control over emotions than do younger adults, they reason more flexibly about emotion-laden dilemmas and remember emotionally charged information better than neutral facts. Older people also rely more often on emotion-focused forms of coping, as opposed to active, problem-solving approaches.

Conclusions: Core features of personality seem to remain relatively stable throughout adulthood and any marked change in mood or social behavior may indicate a disorder. However, more subtle reordering of personal priorities and shifts in coping styles are common with normal ageing. The richness of emotional processing in older persons runs counter to the generally declining patterns seen in many cognitive and physical skills.

Key-words: elderly, older adults, aging, personality traits, emotions. 